\title{
Distribution of boundary shear in compound channel with rough floodplains
}

\author{
K. C. Patra, N. Sahoo \& K. K. Khatua \\ Department of Civil Engineering, National Institute of Technology, India
}

\begin{abstract}
For uniform bounded flow conditions, much of the hydraulic resistance may be attributed to grain roughness and flow characteristics with further accounting for other forces. The resistance to flow by the channel boundary is manifested in the form of distribution of boundary shear along the periphery. In the present work, the validated equations of shear stress distributions across the boundary of main channel and roughened flood plain are analyzed and tested for compound channel having high width ratio of 15.75 and their flow conditions using fresh lab data recorded for this purpose as well as for FCF data for a better comparison.

Keywords: open channel, compound channel, boundary shear, roughness, overbank flow.
\end{abstract}

\section{Introduction}

In a natural channel the flood plains are generally wider and rougher than the main channel. The flow process in the open channel becomes more complicated at over bank stages due to the different hydraulic conditions prevailing in the main channel and the adjoining floodplains. For over bank stage, the resulting velocity distribution is generally not uniform across the cross-section; in particular the velocity tends to be higher in deeper main channel than the shallower flood plain, as in these compound channels the shallow floodplains offer more resistance to flow than the deep main channel. The velocity variation raise lateral momentum transfer between the deep main channel section and the adjoining shallow floodplains, which further complicates the flow process, leading to the uneven distribution of shear stress in the main channel and floodplain peripheral regions. 
It is a great challenge to the river engineers and researchers working in the field to predict the distribution of boundary shear across the wetted perimeter of a given channel for a certain flow-rate. Leighly [1] proposed the idea of using conformal mapping to study the wall shear stress in open-channel flows and pointed out that, in the absence of secondary currents, the wall shear stress acting on the bed must be balanced by the downstream component of the weight of water contained within the bounding orthogonal. Einstein's [2] hydraulic radius separation method is still widely used in laboratory studies and in engineering practices. Following this idea the works of Knight and MacDonald [3], Knight [4], Noutsopoulos and Hadjipanos [5], Knight et al. [6], $\mathrm{Hu}$ [7] and Patel [8] have led to an improved understanding of the lateral distributions of wall shear stress in rectangular channels, prismatic channels and ducts. More contributions by Patra and Kar [9], Khatua and Patra [10], Khatua et al. [11] towards the boundary shear stress distribution in meandering as well as straight compound channels having smooth surface is worthy to discuss.

Early work by Myers and Elsawy [12], Myers [13], Wormleaton et al. [14], Knight and Demetriou [15], indicated the importance of taking into account the main channel/floodplain interaction effects which were first recognized and investigated by Sellin [16] and Zheleznyakov [17]. In compound channel having rougher flood plain than main channel, the main channel/floodplain interaction increases, Knight and Hamed [18], Myers et al. [19]. This paper aims to study the effect of the variation in roughness of flood plain and main channel having width ratio (width of flood plain/width of main channel) $>15$, on the boundary shear stress distribution along the cross section. For this study, experiments are carried out with roughness variations in the floodplain. A generalized equation is found out for the prediction of the boundary shear distribution across the compound channel sections for different roughness ratios $(\gamma)$, where $\gamma=$ flood plain roughness $\left(n_{f p}\right)$ /main channel roughness $\left(n_{m c}\right)$. The equation is further compared with existing models using the present experimental data and FCF data of the Wallingford, UK.

\section{Experimental setup}

\subsection{Experimental channel}

For the present study experiments are carried out in a straight compound channel fabricated using Perspex sheets and placed inside a tilting flume of dimension $12 \mathrm{~m}$ long, $2 \mathrm{~m}$ wide and $0.6 \mathrm{~m}$ depth, at the Fluid Mechanics Laboratory of the Civil Engineering Department at the National Institute of Technology Rourkela, India. A recirculation system of water supply is established, in which water pumped from an underground sump to an overhead tank from where water could flow to the flume, passes through the experimental channel under gravity and allowed to flow over a rectangular notch before falling to the volumetric tank. From the volumetric tank, water flows back to the underground sump. Detailed geometrical features of the experimental channel are given in Table 1. A sketch of the experimental channel with measuring equipment from downstream side is shown in Fig. 1. 
Table 1: Details of channel geometry of the experimental channel.

\begin{tabular}{|c|l|c|}
\hline $\begin{array}{r}\text { Sl } \\
\text { no. }\end{array}$ & \multicolumn{1}{|c|}{ Item description } & Experimental channel \\
\hline 1 & Channel type & Straight \\
\hline 2 & Geometry of main channel section & Trapezoidal (side slopes 1:1) \\
\hline 3 & Geometry of flood plain section & Rectangular (side slope 0 ) \\
\hline 4 & Flood plain type & Symmetric \\
\hline 5 & Flood plain width $(B)$ & $1.89 \mathrm{~m}$ \\
\hline 6 & Main channel base width $(b)$ & $0.12 \mathrm{~m}$ \\
\hline 7 & Depth of main channel $(h)$ & $0.08 \mathrm{~m}$ \\
\hline 8 & Bed slope of the channel & 0.003112 \\
\hline 9 & Width ratio $(\alpha=B / b)$ & $\mathbf{1 5 . 7 5}$ \\
\hline 10 & Aspect ratio $(\delta=b / h)$ & 1.5 \\
\hline
\end{tabular}

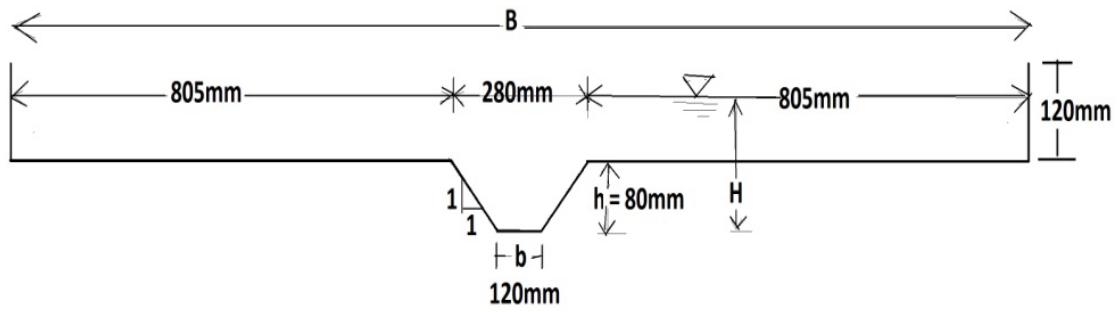

Figure 1: $\quad$ Sketch of the experimental straight compound channel.

\subsection{Design and construction of rough channels}

For the investigation of boundary shear distribution in a rough compound channel, woven wire mesh is used as roughening materials on the flood plain to get rough flood plains. The woven wire mesh is of mild steel with mesh opening size $3 \mathrm{~mm} \times 3 \mathrm{~mm}$ and its wire diameter is measured $0.4 \mathrm{~mm}$.

The experimental results of FCF indicate that the variations of Manning's $n$ with the flow depth are different for the in-bank and overbank flows. With the increasing flow depth, Manning's $n$ returns to the more common value which indicates that Manning's $n$ is the function of flow depth at a low flow depth for the overbank flows. Composite roughness also varies with depth of flow. To avoid this complexity, Manning's $n$ value of the Perspex sheet and wire mesh are obtained from in-bank flow experiments conducted in the simple trapezoidal channel separately (Fig. 2(a) and (b)). The mean values of roughness coefficient $n$ from the in-bank flow for the Perspex sheet and wire mesh are adopted as material roughness coefficients for overbank flow conditions in the present study, which are 0.00983 and 0.01097 respectively. This procedure of Manning's $n$ determination of a material is adopted by many investigators for their studies following the works of Myers and Brennan [20], Ayyoubzadeh [21] and Atabay and Knight [22]. 


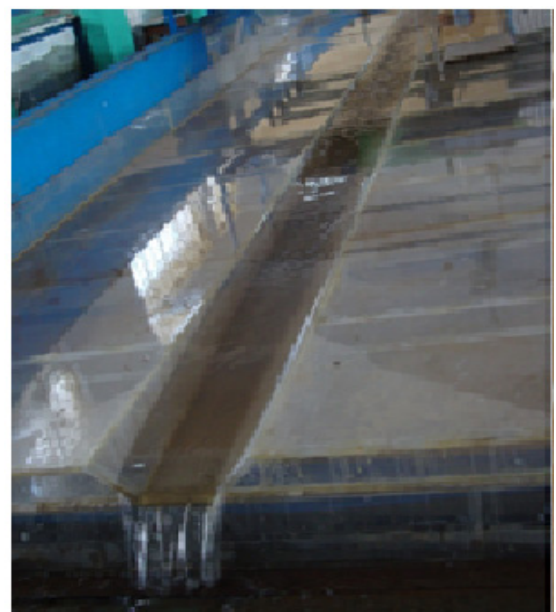

(a)

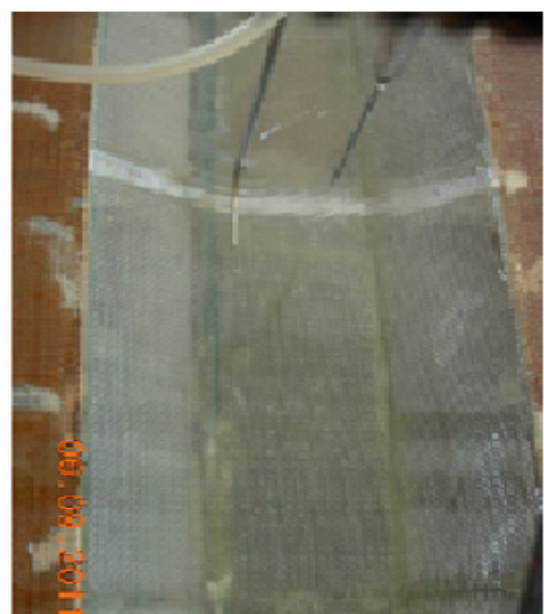

(b)

Figure 2: $\quad$ Photographs of in-bank flow for determination of Manning's $n$ of Perspex sheet and wire-mesh.

This material is glued to the flood plain perimeter to make it rough. In every experiment the roughness ratio (i.e. $n_{f p} / n_{m c}$ ) is changed, keeping floodplain bed rougher than the main channel. In the present study as the wetted perimeter of floodplain wall is less than $3 \%$ of the total wetted perimeter, the composite roughness of the flood plain is not considered, rather the bed roughness of the flood plains is considered for each series. All the differently designed channels are categorized in terms of $\gamma$ and given in Table 2. Photographs of the experiments are shown in Figs. 3(a) and (b).

Table 2: $\quad$ Surface conditions of overbank series.

\begin{tabular}{|c|c|c|c|c|c|}
\hline Series & $\begin{array}{c}\text { Main channel } \\
\text { boundary }\end{array}$ & $\begin{array}{c}\text { Floodplain } \\
\text { bed }\end{array}$ & $\begin{array}{c}\text { Floodplain } \\
\text { wall }\end{array}$ & Named & $\gamma=n_{f p} / n_{m c}$ \\
\hline 1 & Smooth & Smooth & Smooth & Smooth & 1 \\
\hline 2 & Smooth & Mesh rough & Mesh rough & Rough & 1.12 \\
\hline
\end{tabular}

\subsection{Slope, discharge and velocity measurement}

A recirculation system of water supply is established with pumping of water from an underground sump to an overhead tank from where water flows under gravity to the flume.

The water surface slope measurement is carried out using a pointer gauge fitted to the travelling bridge operated manually having a least count of $0.1 \mathrm{~mm}$. The slope of the channel bed is found out $3.112 \times 10^{-3}$. In the present study, it is assumed that the channel bed slope is equal to the energy gradient slope. 


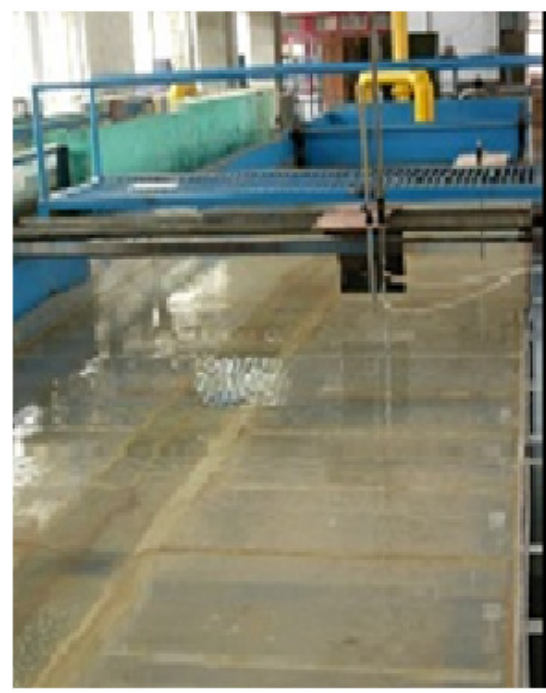

(a) Smooth

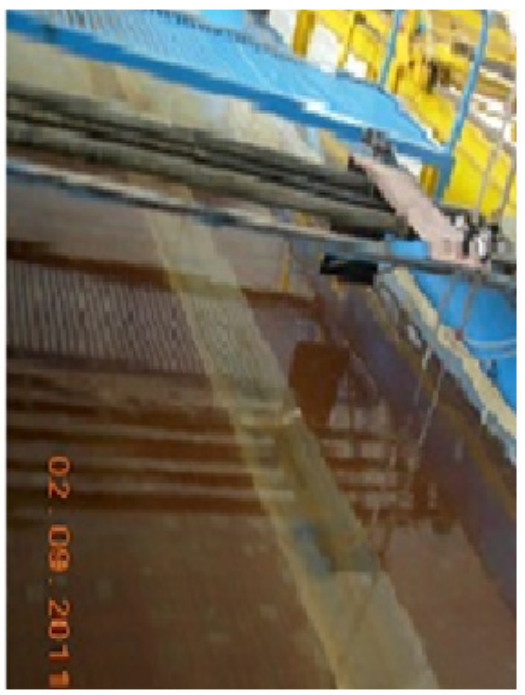

(b) Rough

Figure 3: Photographs while experimenting with different surface conditions.

For discharge measurement, the rectangular notch installed at the end of the experimental flume needed calibration for the particular slope. The coefficient of discharge $\left(C_{d}\right)$ of the rectangular notch was found out as 0.6792 by calibrating it with the actual flow in the volumetric tank.

As the compound channel is symmetric, boundary shear stress measurements are taken at successive points on half of its total wetted perimeter. For measurement of boundary shear stress a pitot tube of circular section having outer diameter $6.33 \mathrm{~mm}$ is used for velocities and shear stresses at required points in the experiments of the present study.

\section{Results and discussions}

\subsection{Stage-discharge relationship}

Here, the stage of flow is the normal depth on the flood plain in the compound channel, which can carry a particular flow only under steady and uniform condition. The stage discharge curves are plotted for different channel roughness (for $\gamma=1$ and $\gamma=1.12$ ) shown in Fig. 4.

For a channel having $\gamma=1$, discharge is found to increase more than that of $\gamma=1.12$ with respect to the depth of flow and discharge of $\gamma=1.12$ gradually becomes closer to $\gamma=1$ as the depth of flow increases, that is, roughness effect on flow decreases slowly with increase in depth of flow. 


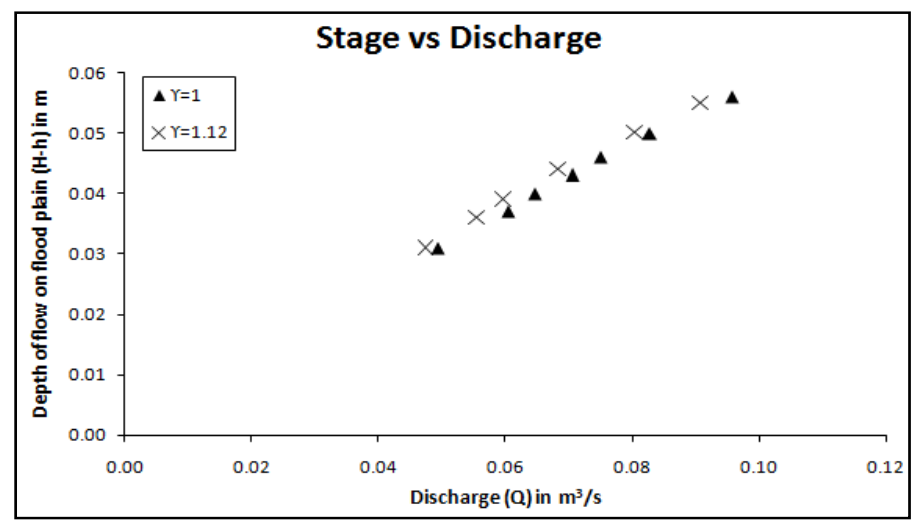

Figure 4: Stage-discharge relationship for different roughness conditions.

\subsection{Evaluation of boundary shear by Preston tube technique}

Based on the assumption of an inner law relating the local shear to the velocity distribution near the wall, Preston [23] developed a simple technique for measuring local shear $\left(\tau_{0}\right)$ in a turbulent boundary layer using a Preston tube (Pitot tube). The tube is placed in contact with the surface. Assessment of the near wall velocity distribution is empirically inferred from the differential pressure $(\Delta p)$ between total and static pressure at the wall. The main difficulty of this method is obtaining the most appropriate calibration equation or curve for the given tube diameter. Preston suggested a non-dimensional relationship between differential pressure $(\Delta p)$ and $\tau_{0}$ as

$$
\frac{\Delta p}{\rho} \frac{d^{2}}{v^{2}}=F\left[\frac{d^{2} \tau_{o}}{\rho v^{2}}\right]
$$

where functional relationship $F$ needs to be determined. Preston proposed the following calibration equations

$$
y^{\prime}=0.875 x^{\prime}-1.396 \text { for } 4.1 \leq x^{\prime} \leq 6.5
$$

where

$$
x^{\prime}=\log _{10}\left(\left(\Delta P d^{2}\right) /\left(4 \rho v^{2}\right)\right) \quad \text { and } \quad y^{\prime}=\log _{10}\left(\left(\tau_{0} d^{2}\right) /\left(4 \rho v^{2}\right)\right) .
$$

in which $v=$ kinematic viscosity, $d=$ the outer diameter of the Preston tube, $\rho=$ density of the flowing fluid. Patel [24] proposed a relationship for $F$ that is valid in three ranges as below

$$
\begin{gathered}
y^{\prime}=0.5 x^{\prime}+0.037 \text { for } y^{\prime} \leq 1.5 \\
y^{\prime}=0.8272-0.1381 x^{\prime}+0.1437 x^{\prime 2}-0.006 x^{\prime 3} \text { for } 1.5<y^{\prime} \leq 3.5
\end{gathered}
$$




$$
x^{\prime}=y^{\prime}+2 \log _{10}\left(1.95 y^{\prime}+4.10\right) \text { for } 3.5<y^{\prime} \leq 5.5
$$

The technique has been widely used for measurement of boundary shear stresses for smooth and rough open channels (Ackerman et al. [25], Al-Khatib and Dmadi [26], Fernholz et al. [27]). In the present study this technique has been used to measure the boundary shear.

Local boundary shear $\left(\tau_{0}\right)$ on the wetted perimeter of the compound channels for different $\gamma$ values is measured by the Preston tube technique and using equation (3). The numerical integration of the shear force over the entire boundary is carried out to give the overall shear force for the whole cross section. The experimental overall mean shear $\left(\tau_{e}\right)$ integrated over the section thus obtained is further compared with the overall mean shear $(\tau)$ value obtained by the energy gradient method using the equation given as:

$$
\tau=\rho g R S
$$

where $g=$ gravitational acceleration, $\rho=$ density of flowing fluid, $S=$ slope of the energy line, $R=$ hydraulic radius of the channel cross section $(A / P), A=$ area of channel cross section, and $P=$ wetted perimeter of the channel section. The mean errors between $\tau$ and $\tau_{e}$ for $\gamma=1$ and 1.12 are found to be $5.93 \%$ and $3.83 \%$ respectively. The variation of $\% S F_{f p}$ w.r.t. $\beta$ for different $\gamma$ values is shown in Fig. 5. It shows that the rate of increase of $\% S F_{f p}$ with respect to $\beta$ decreases with increase in $\gamma$ value.

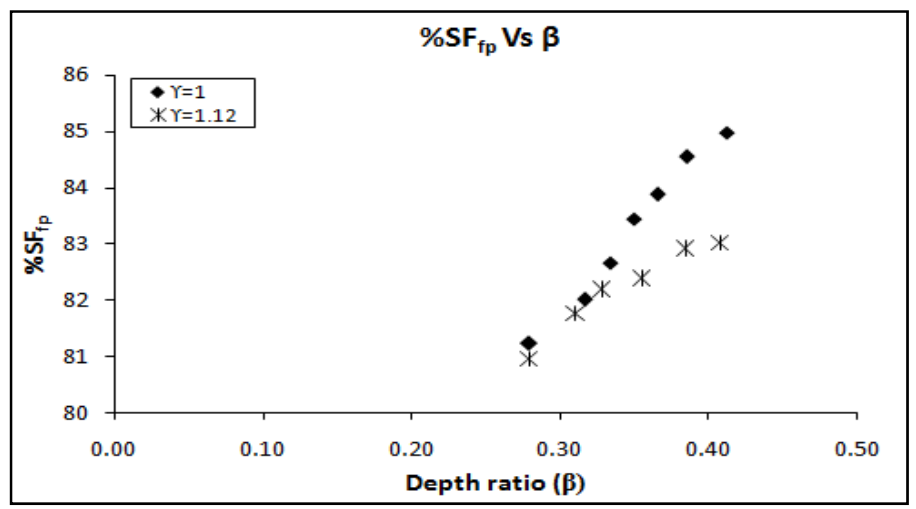

Figure 5: $\quad$ Variation of $\% S F_{f p}$ with respect to $\beta$ for different $\gamma$ values.

\subsection{Analysis for boundary shear distribution in rough compound channels}

Knight and Hamed [18] investigated boundary shear force distribution for rectangular compound channel, whose floodplain was roughened by strip roughness. To study the influence of differential roughness between the floodplains and the main channel, the distance between strip roughness materials was increased or decreased for the floodplains while the main channel kept 
smooth. They proposed equation for the percentage of total shear force carried by the floodplain $\left(\% S F_{f p}\right)$ as:

$$
\% S F_{f p}=48(\alpha-0.8)^{0.289}(2 \beta)^{1 / m}(1+1.02 \sqrt{\beta} \log \gamma)
$$

where $m$ can be calculated from the relation

$$
m=1 /\left(0.75 e^{0.38 \alpha}\right)
$$

in which $\alpha$ = width ratio of the compound channel $(B / b), B=$ flood plain width, $b=$ main channel width, $\beta=$ depth ratio $(H-h) / H, H=$ depth of flow on the main channel, $h=$ depth of flow on the flood channel, $\gamma=$ the ratio of Manning's roughness $n$ of the floodplain $\left(n_{f p}\right)$ to that of the main channel $\left(n_{m c}\right)$. Equation (5) is validated for low width ratio of $\alpha=4$ and $1 \leq \gamma \leq 3$. Further due to complexity of the empirical equation (5), Khatua and Patra [10] modified it to a simple equation for predicting the percentage of floodplain shear force carried by floodplains in compound channel having different roughness in main channel and flood plain surface for a ranges of $2 \leq \alpha \leq 4$, as:

$$
\% S F_{f p}=1.23 \beta^{0.1833}(38 \operatorname{Ln} \alpha+3.6262)[1+1.02 \sqrt{\beta} \log \gamma]
$$

in which $\alpha, \beta$ and $\gamma$ has the same meaning as defined in equation (5). Khatua et al. [11] further improved these equations to predict $\% S F_{f p}$ for compound channel, when they found equations (5) and (6) give errors of more than $70 \%$ for $\alpha=6.67$. They proposed equation for $\% S F_{f p}$ as a function of $\% A_{f p}$, which in terms of $\alpha$ and $\beta$ is given as

$$
\% S F_{f p}=4.105\left[\frac{100 \beta(\alpha-1)}{1+\beta(\alpha-1)}\right]^{0.6917}
$$

where $\alpha$ and $\beta$ are defined earlier. Equation (7) is meant for compound channel having homogeneous roughness, i.e. $\gamma=1$. The above approaches are applied to the present experimental data as well as the large channel facility (FCF) data of the Wallingford, UK. The percentage of error in estimating $\% S F_{f p}$ by each method is calculated. If $S_{c}$ represents the calculated $\% S F_{f p}$ and $S_{m}$ the measured $\% S F_{f p}$, the percentages of error for each series of experimental runs are computed using the equation:

$$
\% \text { Error }=100 \times \frac{S_{c}-S_{m}}{S_{m}}
$$

Graphs between the percentage of error of $S F_{f p}$ and depth ratios b for smooth and rough channels is plotted in Fig. 6 and that for FCF channel is in Fig. 7. From the figures Khatua et al. [11] method can be seen to give better estimate of $\% S F_{f p}$ results as compared to the models of Knight and Hamed [18] and Khatua and Patra [10]. In Fig. 6, it is seen that Khatua et al. [11] method gives mean error of $5.28 \%$ with a standard deviation of $0.29 \%$ for $\gamma=1$; while for $\gamma=1.12$ it increases to $6.44 \%$ with a standard deviation of $0.69 \%$ for the recent lab data $(\alpha=15.75)$. Similarly in Fig.7 for FCF data (for $\alpha=4.2$ and $0.1<\beta<0.5$ ), 


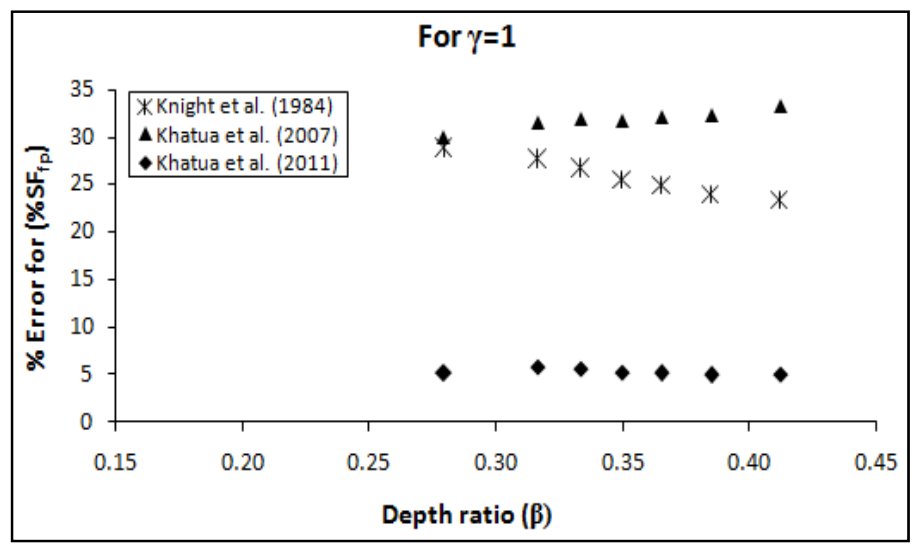

(a)

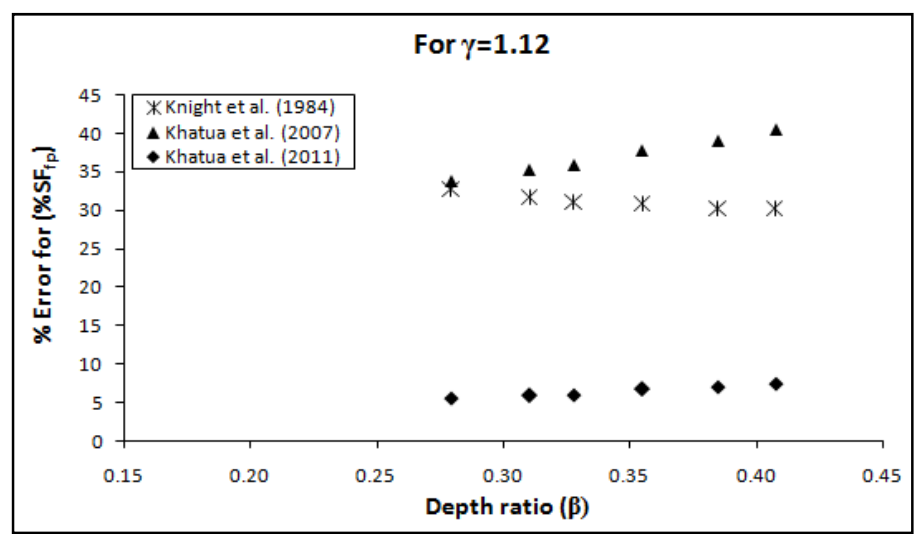

(b)

Figure 6: Percentage of error in calculating $\% S F_{f p}$ for recent lab data $(\alpha=15.75)$.

Khatua et al. [11] method gives a mean error of $+4.72 \%$ with a standard deviation of $0.82 \%$ for $\gamma=1$; while for $\gamma=3.08$ the error increases to $+79.51 \%$ with a standard deviation of $19.43 \%$.

Although the Khatua et al. [11] method exhibits reasonable accuracy for lower $\gamma$ value (i.e. $1 \leq \gamma \leq 1.12$ ), at high width ratio it shows significant errors up to $102.11 \%$ for higher $\gamma$ value at low width ratio as it was meant for homogeneously roughened compound channel (i.e. $\gamma=1$ ). However, all the methods are found to give poor results when applied to rough channels of higher roughness ratio $(\gamma)$ values. 


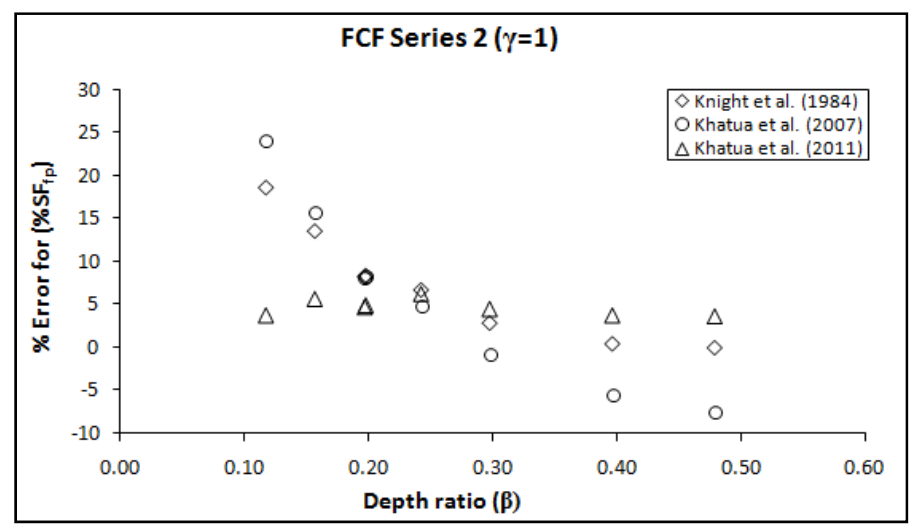

(a)

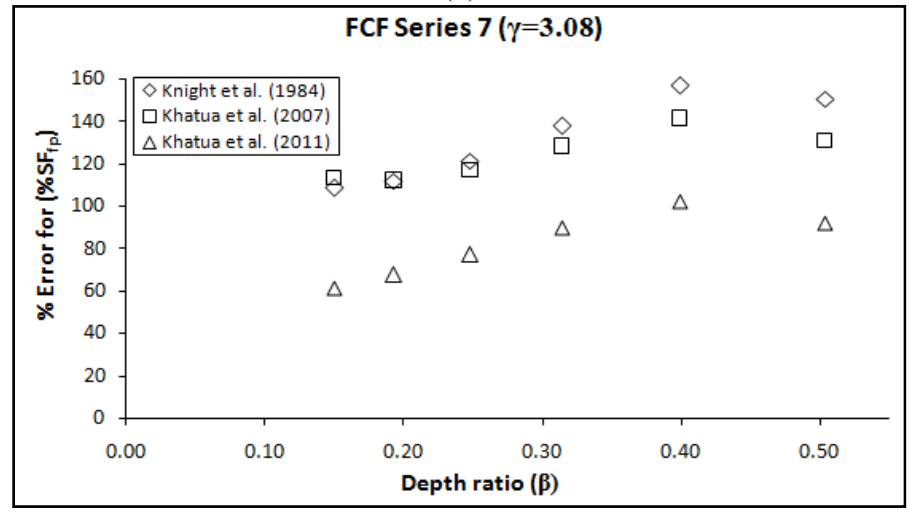

(b)

Figure 7: $\quad$ Percentage of error in calculating $\% S F_{f p}$ for FCF data $(\alpha=4.2)$.

\section{Conclusions}

- An attempt is made to study the boundary shear force distribution between a main channel and floodplain in a compound channel for higher width ratio $(a>$ 10) having a smooth main channel and smooth/rough floodplains.

- The $\% S F_{f p}$ are found to increase with $\beta=((H-h) / H)$ for all channels. However, the increment is found to be less for rough channels.

- Method III of estimating $\% S F_{f p}$ for recent series of lab data and FCF data, consistently gives more accurate results than method I and method II

- Method III gives maximum error around 5\% for $\gamma=1$, while for $\gamma=1.12$ it increases to $7.5 \%$ for the recent lab data $(a=15.75)$.

- For FCF data $(\alpha=4.2,0.1<\beta<0.5)$, method III gives mean error for $\gamma=1$ as $+4.7 \%$ with standard deviation of $0.82 \%$, while for $\gamma=3.08$ the error increases to $+79.51 \%$ with standard deviation of $19.43 \%$ that needs more study. 


\section{References}

[1] Leighly, J.B., Toward a theory of the morphologic significance of turbulence in the flow of water in streams. Univ. of Calif. Publ. Geography, 6(1), pp. 1-22, 1932.

[2] Einstein, H.A., Formulas for the transportation of bed-load. Trans., ASCE, 107, pp. 561-597, 1942.

[3] Knight, D.W. \& MacDonald, J.A., Open-channel flow with varying bed roughness. J. Hydr. Div., ASCE, 105(9), pp. 1167-1183, 1979.

[4] Knight, D.W., Boundary shear in smooth and rough channels. J. Hydr. Div., ASCE, 107(HY7), 1981.

[5] Noutsopoulos, G.C. \& Hadjipanos, P.A., Discussion of "Boundary shear in smooth and rough channels by D.W. Knight". J. Hydr. Div., ASCE, 108(HY6), pp. 809-812, 1982.

[6] Knight, D.W., Demetriou, J.D. \& Hamed, M.E., "Boundary shear in smooth rectangular channels." J. Hydr. Eng., ASCE, 110(4), pp. 405-422, 1984.

[7] Hu, C.H., The effect of the width/depth ratio and side-wall roughness on velocity profile and resistance in rectangular open-channels. MS thesis, Tsinghua Univ., Beijing, 1985.

[8] Patel, H.S., Boundary shear in rectangular and compound ducts. PhD Thesis. The University of Birmingham, 1984.

[9] Patra, K.C., \& Kar, S.K., Flow interaction of Meandering River with Flood plains, J. Hydr. Eng., ASCE, 126(8), pp. 593-603, 2000.

[10] Khatua, K.K. \& Patra, K.C., Boundary shear stress distribution in compound open channel flow. J. Hydr. Eng., ISH, 12(3), pp. 39-55, 2007.

[11] Khatua, K.K., Patra, K.C. \& Mohanty, P.K., Stage-Discharge prediction for straight and smooth compound channels with wide floodplains. J. Hydr. Eng., ASCE, (HY1943), 2011.

[12] Myers, W.R.C., \& Elsawy, E.M., Boundary shear in channel with flood plain. J. Hydr. Div., ASCE, 101(HY7), pp. 933-946, 1975.

[13] Myers, W.R.C., "Momentum Transfer in a Compound Channel," J. Hydr. Res., IAHR, 16(2), pp. 139-150, 1978.

[14] Wormleaton, P.R., Allen, J. \& Hadjipanos, P., Discharge assessment in compound channel flow. J. Hydr. Div., ASCE, 108(HY9), pp. 975-994, 1982.

[15] Knight, D.W. \& Demetriou, J.D., Floodplain and main channel flow interaction. J. Hydr. Eng., ASCE, 109(8), pp. 1073-1092, 1983.

[16] Sellin, R.H.J., A laboratory investigation into the interaction between flow in the channel of a river and that of its flood plain. La. Houilte Blanche, (7), pp. 793-801, 1964.

[17] Zheleznyakov, G.V., Interaction of channel and flood plain streams. $14^{\text {th }}$ Congress of the IAHR, Paris, France, 5, pp. 144-148, 1971.

[18] Knight, D.W. \& Hamed, M.E., Boundary shear in symmetrical compound channel. J. Hydr. Eng., ASCE, 110(10), pp. 1412-1430, 1984. 
[19] Myers, W.R.C., Lyness, J.F., Cassells, J., Influence of boundary roughness on velocity and discharge in compound river channels. J. Hydr. Res. 39(3), pp. 311-319, 2001.

[20] Myers, W.R.C. \& Brennan, E.K., Flow resistance in compound channels. J. Hydr. Res., 28, pp. 141-155, 1990.

[21] Ayyoubzadeh, S.A., Hydraulic aspects of straight compound channel flow and bed load sediment transport. Ph D thesis, The University of Birmingham, England, U.K., 1997.

[22] Atabay, S. \& Knight, D.W., 1-D modeling of conveyance, boundary shear and sediment transport in overbank flow. J. Hyd. Res. 44(6), pp. 739-754, 2006.

[23] Preston, J.H., The determination of turbulent skin friction by means of Pitot tubes. J. R. Aeronaut. Soc., 58, pp. 109-121, 1954.

[24] Patel, V.C., Calibration of the Preston tube and limitations on its use in pressure gradients. J. Fluid Mechanics, 23(Part 1), pp. 185-208, 1965.

[25] Ackerman, J.D., Wong, L., Ethier, C.R., Allen, D.G., \& Spelt, J.K., Preston-static tubes for the measurement of wall shear stress. J. Fluids Eng., 116, pp. 645-649, 1994.

[26] Al-Khatib, I.A., \& Dmadi, N.M., Boundary shear stress in rectangular compound channels. Tr. J. Eng. and Environ. Sc., 23, pp. 9-18, 1999.

[27] Fernholz, H.H., Janke, G., Schober, M., Wagner P.M., and Warnack, D., New developments and applications of skin friction measuring techniques. Meas. Sci. Technol. 7, pp. 1396-1409, 1996. 